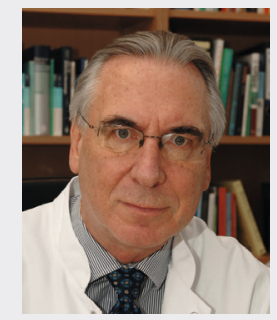

Prof. Dr. Gerd Burchard

\title{
Reisemedizin als Querschnittsfach
}

Liebe Kolleginnen und Kollegen,

die Artikel der vorliegenden Ausgabe decken wieder das ganze Spektrum der Reisemedizin und Tropenmedizin ab.

Die Flugmedizin ist dieses Mal nicht direkt vertreten - aber aufgenommen wurde ein Artikel über die Höhenmedizin. Es geht um die Vorbereitung für Trekking und Höhenbergsteigen, also ein Thema, das für jeden, der reisemedizinische Beratungen macht, relevant ist.

Ein weiterer Artikel aus der Berg- und Expeditionsmedizin beschäftigt sich mit Lawinenunfällen. Insbesondere werden die aktuellen Empfehlungen zum Management von Lawinenverschütteten erläutert. Ein spezielles, aber sicher sehr wichtiges Thema.

Zur Tropenmedizin finden Sie in diesem Heft - aus meiner Sicht - 3 sehr wichtige und aktuelle Themen: Ein Artikel beschäftigt sich mit tropischen Infektionserregern bei schwangeren Migrantinnen, es werden aktuelle Daten genannt und konkrete Handlungsempfehlungen gegeben. Ein weiterer Artikel beschreibt die Wechselwirkungen zwischen Malariamedikamenten und einer antiretroviralen Therapie - die Bedeutung liegt auf der Hand. Und Sie finden in diesem Heft schließlich noch einen Artikel zur notfallmäßigen Selbstbehandlung der Malaria. Diese Strategie wird von der Deutschen Gesellschaft für Tropenmedizin und Internationale Gesundheit (DTG) ja grundsätzlich vorgeschlagen bei Reisen in Gebiete mit geringem Transmissionsrisiko - das Übertragungsrisiko wird als gering definiert, wenn zuletzt in diesem Gebiet nur 1-10 dokumentierte Fälle einer Malaria pro Jahr pro 100000 Reisende aufgetreten sind. Herr Brehm et al. stellen - aus meiner Sicht - sehr gut dar, dass dieses Konzept im Einzelfall hinterfragt werden muss, nicht jeder Reisende in diesen Gebieten benötigt ein Malariamedikament in der Tasche.

Hoffentlich haben Sie beim Lesen dieser Ausgabe viel Freude. 